\title{
Crustal velocity structures beneath North China revealed by ambient noise tomography*
}

\author{
Lihua Fang ${ }^{1, \uparrow} \quad$ Jianping $\mathrm{Wu}^{1} \quad$ Zhifeng Ding ${ }^{1}$ \\ Weilai Wang $^{1}$ and Giuliano Francesco Panza ${ }^{1,2,3}$
}

\author{
${ }^{1}$ Institute of Geophysics, China Earthquake Administration, Beijing 100081, China \\ ${ }^{2}$ Department of Earth Sciences, University of Trieste, Trieste 34127, Italy \\ ${ }^{3}$ The Abdus Salam International Center for Theoretical Physics, Earth System Physics Section, Trieste 34151, Italy
}

\begin{abstract}
We collected continuous noise waveform data from January 2007 to February 2008 recorded by 190 broadband and 10 very broadband stations of the North China Seismic Array. The study region is divided into grid with interval $0.25^{\circ} \times 0.25^{\circ}$, and group velocity distribution maps between $4 \mathrm{~s}$ and $30 \mathrm{~s}$ are obtained using ambient noise tomography method. The lateral resolution is estimated to be $20-50 \mathrm{~km}$ for most of the study area. We construct a 3-D S wave velocity model by inverting the pure path dispersion curve at each grid using a genetic algorithm with smoothing constraint. The crustal structure observed in the model includes sedimentary basins such as North China basin, Yanqing-Huailai basin and Datong basin. A well-defined low velocity zone is observed in the Beijing-Tianjin-Tangshan region in 22-30 km depth range, which may be related to the upwelling of hot mantle material. The high velocity zone near Datong, Shuozhou and Qingshuihe within the depth range of 1-23 km reveals stable characteristics of Ordos block. The Taihangshan front fault extends to $12 \mathrm{~km}$ depth at least.
\end{abstract}

Key words: seismic noise; surface wave tomography; velocity structure; genetic algorithm; North China CLC number: P315.2 Document code: A

\section{Introduction}

North China is one of the most seismically active areas in China. Historical strong earthquakes occurred frequently in this area. More than 200 earthquakes with magnitude greater than 5.0 have occurred in this region since $780 \mathrm{BC}$, among which 37 events are larger than $M 6.0$ and 10 events larger than M7.0 (Department of Earthquake Disaster Prevention, China Seismological Administration, 1995, 1999; China Earthquake Network Center, 2008). In 1679, an earthquake of $M 8.0$ occurred in Sanhe, which is the largest one among the known historical earthquakes in this region. The 1976 Tangshan earthquake (M7.8) killed at least 240000 people, and is one of the most destructive earthquakes in human history. A detailed investigation of the crustal structure and

\footnotetext{
* Received 14 May 2010; accepted in revised form 19 July 2010; published 10 October 2010 .

^ Corresponding author. e-mail: flh@cea-igp.ac.cn

(C) The Seismological Society of China and Springer-Verlag Berlin Heidelberg 2010
}

seismotectonics of this region is very important for understanding the physical mechanism of continental earthquakes and assessment of seismic hazard and mitigation of seismic risks.

The study region is in eastern part of North China (Figure 1a). The central part of the study area is North China basin (NCB). NCB is a large intracontinental basin where many horst and graben basins have developed since Cenozoic. NCB can be divided into two major internal uplifts (Chengning, Cangxian) and four major depressions (Jizhong, Huanghua, Jiyang, and Linqing) (Chang, 1991). The northeastern part of the study area is the relatively stable Yanshan uplift with its major structure and tectonics oriented in $\mathrm{E}-\mathrm{W}$ direction and the western and northwestern portions are Taihangshan uplift region with some small intermountain basins. To the southeast is the Luxi uplift, and to the east the Bohai bay. In the NCB and the Taihangshan uplift region there are many active faults oriented in NE-SW direction. In the two regions, most of the structures and mountain ranges trend in NE-SW direction. 

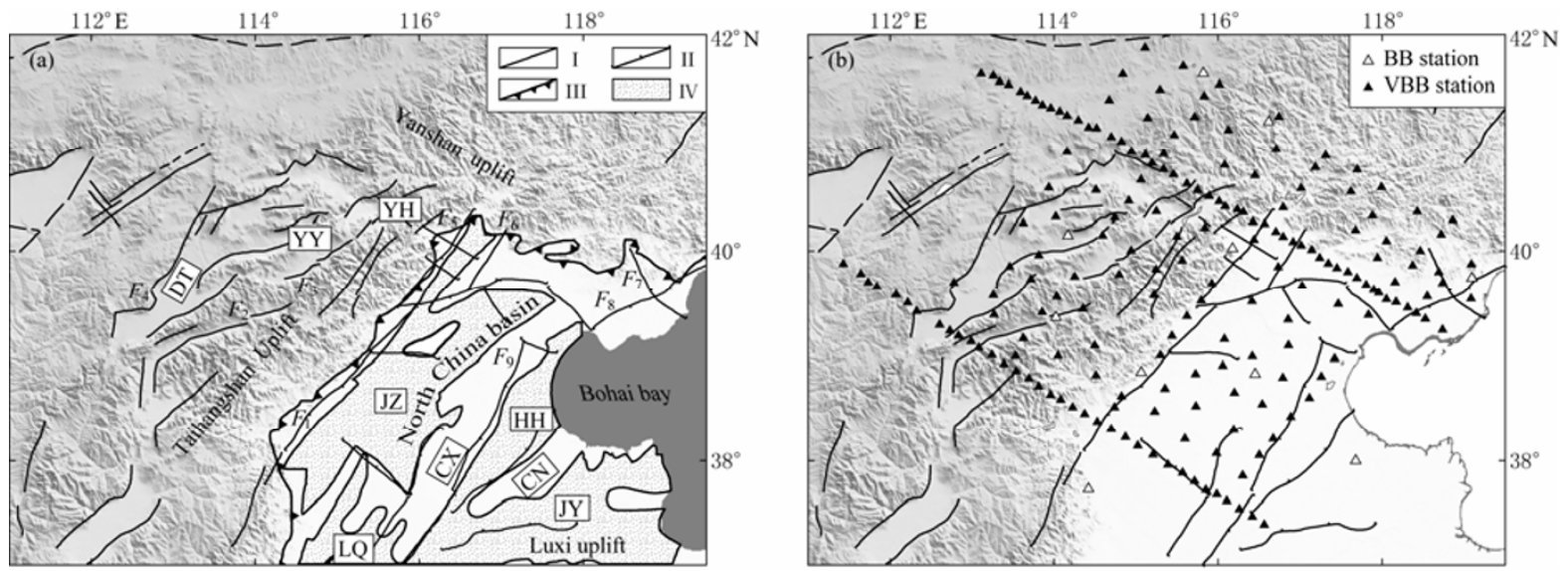

Figure 1 (a) Topography and tectonic sketch map of the study region modified from Wang et al. (1989) and Deng et al. (2004). I. Major faults; II. Deduced faults; III. Boundary of Cenozoic basins; IV. Depression areas in North China basin. The major faults are Taihangshan fault $\left(F_{1}\right)$, Wutaishan fault $\left(F_{2}\right)$, Yuxian-Yanqing fault $\left(F_{3}\right)$, Kouquan fault $\left(F_{4}\right)$, Nankou-Sunhe fault $\left(F_{5}\right)$, Xiadian-Fengheying fault $\left(F_{6}\right)$, Luanxian-Leting fault $\left(F_{7}\right)$, Changli-Ninghe fault $\left(F_{8}\right)$, and Cangxian fault $\left(F_{9}\right)$. The basins and major geological units are Yanqing-Huailai basin (YH), Yangyuan-Yuxian basin (YY), Datong basin (DT), Jizhong depression (JZ), Huanghua depression (HH), Jiyang depression (JY), Linqing depression (LQ), Cangxian uplift (CX), and Chengning uplift $(\mathrm{CN})$. (b) Distribution of the broadband (BB) and very broadband (VBB) seismic stations used in this study.

Extensive geophysical investigations have been conducted in the North China craton using seismic reflection and refraction experiments (Teng et al., 2003; Li et al., 2006) and body wave tomography methods (Huang and Zhao, 2004; Qi et al., 2006; Lei et al., 2008). The earlier results mainly focused on $\mathrm{P}$ wave velocity structures. Receiver function method has been used to determine S wave velocity structures (Zheng et al., 2005; Wang et al., 2009b). However, the receiver function inversion can only give velocity structures directly beneath the stations and this method is insensitive to absolute $\mathrm{S}$ wave velocitiy. Many surface wave tomography studies have also been conducted (e.g., Feng and Teng, 1983; Ritzwoller and Levshin, 1998; Huang et al., 2003), however, most of them are at scale of Chinese mainland with lateral resolution of the order of several to a few hundred kilometers. Few studies on surface wave in North China have been made because of relatively low seismicity in North China and subsequent logistic limitation resulted from earthquake-based surface wave tomography. Previous studies almost exclusively used teleseismic data, which makes it diffucult to obtain reliable short-period $(<10 \mathrm{~s})$ dispersion measurements due to intrinsic attenuation and scattering along ray paths. However it is the short-period waves that are most useful for constraining the structure of the crust and uppermost mantle. Moreover, the long paths also result in broad lateral sensitivity kernels which limit resolution to hundreds of kilometers. Thus high-resolution surface wave tomography results are scarce in North China.

Recent studies have shown that the ambient noise tomography method is a powerful tool to image velocity structures beneath dense seismic arrays. This method has been successfully applied to several geographical settings, such as Southern California (Sabra et al., 2005; Shapiro et al., 2005), Tibet (Yao et al., 2006), Europe (Yang et al., 2007), New Zealand (Lin et al., 2007), China (Zheng et al., 2008; Li et al., 2009; Fang et al., 2010), and elsewhere in the world, also at very local scale, like in Napoli, Italy (De Nisco et al., 2008).

In this paper, we present the tomography model of the crust and uppermost mantle beneath North China, with special emphasis on crustal velocity structures and their implication in understanding the present day seismotectonic setting of the region and the dynamic evolution of North China. The depth of the velocity model is from surface to about $50 \mathrm{~km}$.

\section{Data and method}

A seismic experiment on North China Seismic Array has been carried out since the winter of 2006. 250 portable stations were deployed in North China, among which 190 are broadband stations, 10 very broadband stations and 50 short period stations. Each station is equipped with Reftek-130B digitizer. The average station separation is about $35 \mathrm{~km}$. Continuous verticalcomponent seismograms, spanning from January 1, 
2007 to February 28, 2008 recorded by 190 broadband stations (Guralp CMG-3ESPC sensor, $60 \mathrm{~s}$ to $50 \mathrm{~Hz}$ flat velocity response) and 10 very broadband stations (Guralp CMG-3T sensor, $120 \mathrm{~s}$ to $50 \mathrm{~Hz}$ flat velocity response), are used in this study (Figure 1b).

The data processing procedure applied here is described in detail in Fang et al. (2010). Now we summarize it briefly. Continuous waveform data are processed one day at a time for each station after being decimated to $1 \mathrm{~Hz}$, bandpass filtered in the period band from $4 \mathrm{~s}$ to $100 \mathrm{~s}$ and after the daily trend, the mean and the instrument response are removed. Then the data are normalized by the running-absolute-mean method. And the last step of preprocessing is to whiten the data over the frequency-band of interest. Then the day-long waveform at each station is correlated with that at each of the other stations and the daily results are stacked to produce the final cross correlation. To simplify the data analysis and to enhance SNR, we average the positive and negative lags of the cross correlation to form 'symmetric signals'. The following analysis is done on the symmetric signals exclusively. Figure 2 shows an example of 14-month stacks of cross correlations plotted as a record section. Clear signals are seen for both positive and negative correlation lags with physically reasonable moveouts $(\sim 3 \mathrm{~km} / \mathrm{s})$ of surface waves propagation.

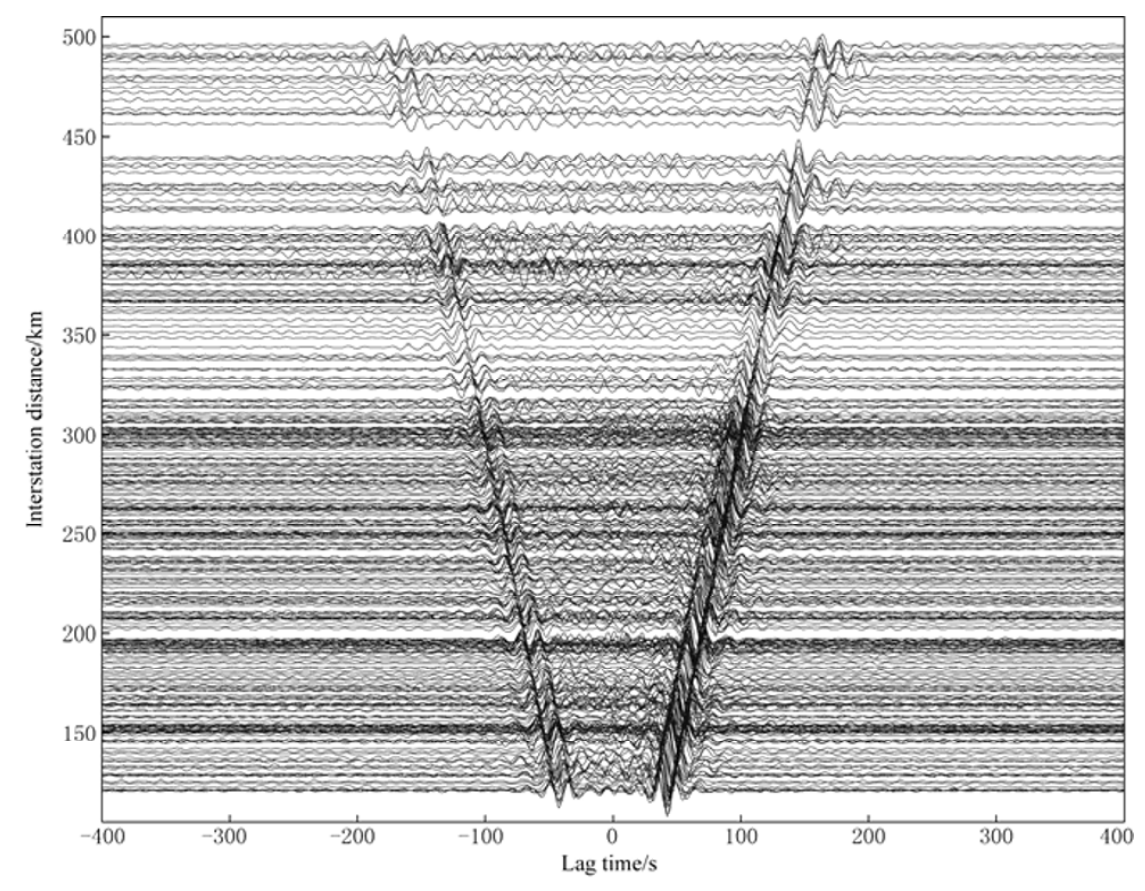

Figure 2 Bandpass filtered (10-50 s) cross correlations as a function of distance and lag time. The cross correlation is time reversed if the amplitude of the negative component is smaller than the amplitude of the positive one. Only cross correlation with SNR greater than 25 are plotted.

Rayleigh wave group velocity dispersion curves are determined using a multiple filter method (Levshin et al., 1992). After data selection, 5630 dispersion curves are used to construct the group velocity maps.

\section{Group velocity maps}

A generalized 2-D linear inversion procedure developed by Ditmar and Yanovskaya (1987) and Yanovskaya and Ditmar (1990) has been applied to constructing the group velocity tomographic maps. Figure 3 shows the ray path distribution (Figures $3 a$ and $3 b$ ) and tomography maps (Figures $3 \mathrm{c}$ and $3 \mathrm{~d}$ ) for $4.5 \mathrm{~s}$ and $20 \mathrm{~s}$, respectively.

As with any tomographic inversion, the resulting maps are not uniquely defined because the initial data do not constrain the seismic velocities at all points of the medium. Therefore, the knowledge of the resolving power is important in order to estimate the minimum really resolvable feature by a given data set and to sort out those features that may be numerical artefacts. Yanovskaya (1997) and Yanovskaya et al. (1998) used the mean size of the averaging area as an estimation of the lateral resolution. Figures $3 \mathrm{e}$ and $3 \mathrm{f}$ show the resolution maps for $4.5 \mathrm{~s}$ and $20 \mathrm{~s}$. The mean size of the 

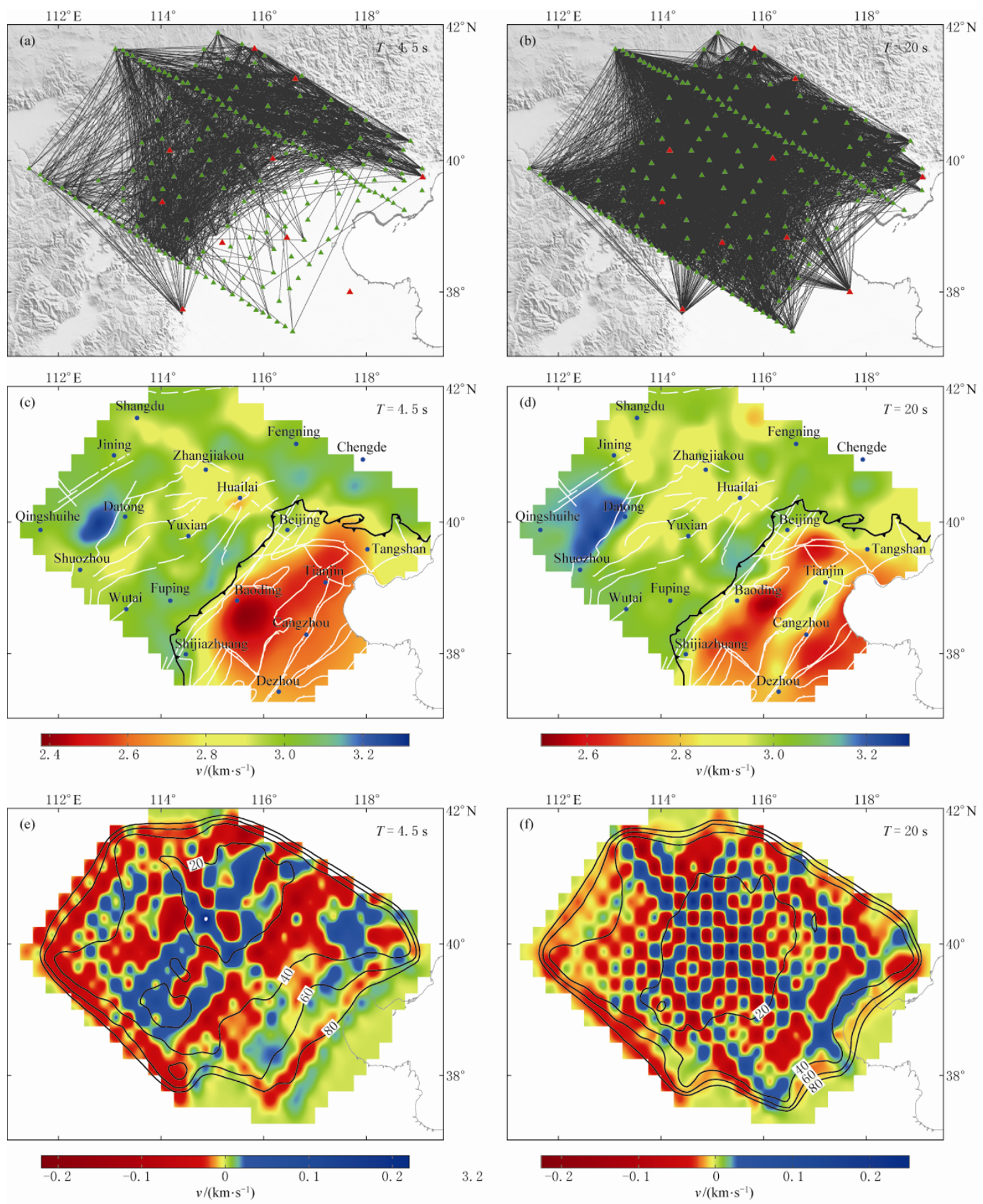

Figure 3 (a) and (b) Inter-station ray path distribution for group velocity measurements at $4.5 \mathrm{~s}$ and $20 \mathrm{~s}$; the broadband stations are shown as green triangles, while the very broadband stations are shown as red triangles. (c) and (d) Group velocity maps for 4.5 $\mathrm{s}$ and $20 \mathrm{~s}$; the cities are shown as blue dots. (e) and (f) Lateral resolution of tomographic maps for $4.5 \mathrm{~s}$ and $20 \mathrm{~s}$; the contours indicate the distribution of the mean size of the average area (in $\mathrm{km}$ ).

averaging area of our tomographic results is of the order of $25 \mathrm{~km}$ in most of the study region, but worsens near the borders of the region due to poor path coverage. This means that the areas of different tectonic structures with 
linear size $>25 \mathrm{~km}$ can be resolved in the inversion. We also perform checkerboard tests (Figures $3 \mathrm{e}$ and $3 \mathrm{f}$ ). The study area is divided into $0.25^{\circ} \times 0.25^{\circ}$ cells and a velocity perturbation of $\pm 7 \%$ with respect to the average group velocity for each examined period is assumed for the cells. Based on this model, travel times along paths between two stations are calculated. Then a solution for the velocity perturbation is obtained with the same parameters as for the real data. The estimations of the resolution obtained from the mean size of the area and the checkerboard tests indicate that the two criteria are equivalent and that it is reasonable to divide the study region into $0.25^{\circ} \times 0.25^{\circ}$ cells and that the anomalies with an area of about $25 \mathrm{~km} \times 25 \mathrm{~km}$ or larger are reliable.

The detailed tomography results are given in Fang et al. (2010), therefore we focus here on their inversion and the interpretation of $\mathrm{S}$ wave velocity structure versus depth.

\section{Structure inversion using genetic algorithm (GA)}

\subsection{GA optimization}

The most important parameters affecting Rayleigh wave propagation are $\mathrm{S}$ wave velocity and layer thickness. Two methods are often used when dispersion curves are inverted. The first is to fix the layer thickness and to invert for $\mathrm{S}$ wave velocity only on the condition that the layers are as thin as possible so that the velocity variation between layers can be obtained. The second is to invert for layer thickness and $\mathrm{S}$ wave velocity simultaneously. In general, the first way increases the uncertainty of inversion result, and rapid oscillations of the solutions are often observed. The second approach can reduce the total number of layers but it increases the computing time. The unconstrained inversion problem is non-linear and will be dealt in detail in another paper.

Here we use an indirect smoothing constraint in GA to invert for dispersion curves (Wu et al., 2001). It is very difficult to apply smoothing constraint to GA inversion directly. If the smoothed models are used in iteration, the diversity of models will be greatly suppressed and all models in the population tend to be similar to each other after a few iterations. The optimal solution can not be guaranteed. Fortunately, we find that if we do not change the new models generated by the selection, crossover and mutation, but modify the model for forward calculation, the smooth constraint can be easily applied to model parameters in GA inversion.
The method can be summarized as follows: the model $v_{\mathrm{S} 0}$ generated by selection, crossover and mutation is smoothed by equation (1) to produce the smoothed model $v_{\mathrm{S}}$, then $v_{\mathrm{S}}$ is used to calculate synthetic dispersion curves. The misfit of model $v_{\mathrm{S} 0}$ is set to be identical to that of $v_{\mathrm{S}}$ and is used for the next iteration. $v_{\mathrm{S}}$ is only used for the forward calculation, but not in the search of the model space. The method is similar to the smoothing constraint used in linear inversion.

$$
\left\{\begin{array}{l}
v_{\mathrm{S}}(h)=\frac{1}{E} \int_{h-h_{0}}^{h+h_{0}} v_{\mathrm{S} 0}(y) \mathrm{e}^{-\sigma(y-h)^{2}} \mathrm{~d} y \\
E=\int_{h-h_{0}}^{h+h_{0}} \mathrm{e}^{-\sigma(y-h)^{2}} \mathrm{~d} y
\end{array}\right.
$$

In equation (1) $v_{\mathrm{S} 0}$ is the velocity model in the GA iteration, $v_{\mathrm{S}}$ is the smoothed model, $h_{0}$ is the number of layers used for smoothing and $h_{0}=3$ in our case; $\sigma$ is the smoothing coefficient, which affects the vertical resolution of the model. In general, the smaller the $\sigma$ is, the smoother the model will be and the lower the vertical resolution is. In the inversion, $\sigma$ can be chosen as a function of depth. For example, $\sigma$ can be selected larger near the surface layer and Moho than at other depths in order to fit the possible large velocity gradients.

For surface waves, the vertical resolution decreases with increasing depth (Panza, 1981). So, in inversion, we often construct a model with relatively thin layers in the crust and relatively thick layers in the mantle. According to our experience, if the layer is thin (less than $3 \mathrm{~km}$ ), the smoothing parameter can be set as $0.2-0.4$; if the layer is thick (more than $5 \mathrm{~km}$ ), the smoothing parameter can be set as $0.5-0.7$. The smoothing parameters also vary with depth. At shallow depth, it can be set as $\sim 0.6$; at Moho and other discontinuities, the smoothing value can be set as $\sim 1.3$.

The key element for any kind of optimization tool is the model evaluation, which is performed by means of an objective function $\Phi$ that allows a quantitative estimation of the model. We consider the root-mean square value of the difference between the observed and calculated group velocities as follows:

$$
\Phi=\sqrt{\frac{1}{n} \sum_{i=1}^{n}\left(v_{i}^{\mathrm{obs}}-v_{i}^{\mathrm{cal}}\right)^{2}},
$$

where $n$ represents the number of observed period-velocity couples, $v_{i}^{\text {obs }}$ is the observed group velocity at the $i$ th period and $v_{i}^{\text {cal }}$ is the calculated velocity for the considered model (individual of the current population). This kind of formulation is also referred to as the $\mathrm{L}_{2}$-norm. 


\subsection{Parameterization and priori constraints}

Model parameterization strongly affects inversion results (Panza, 1981; Pontevivo and Panza, 2006). If the inversion is too weakly constrained, there will be a broad subset of models that fit the data and large uncertainties will appear at each depth. Whereas, too tight constraints on the model space will reduce the uncertainty in the estimated parameters, but the model will be increasingly subject to systematic errors and may miss relevant features of the study area.

A priori constraints on the model parameters are important not only to speed the inversion by limiting the volume of the model space searched, but also to define what we judge to be physically reasonable or plausible candidate models (e.g., Pontevivo and Panza, 2006). For these reasons, we collect the seismic reflection and refraction data, receiver function inversion data and receiver function $h-k$ stack results (State Seismological Bureau, 1986; Xu and Zheng, 2005; Zheng et al., 2005; Luo et al., 2008; Wang et al., 2009a; Wang et al., 2009b).

The thickness of each layer is set to be $1-2 \mathrm{~km}$ in the crust, and $5-10 \mathrm{~km}$ in the mantle. The variation range of the Moho depth is determined according to deep seismic sounding (DSS) data and receiver function $h-k$ stack results. In the inversion, we did not fix the depth of the Moho interface, but design a five-layer model with $1 \mathrm{~km}$ thickness near the Moho interface. $\mathrm{S}$ wave velocities near the surface $(0-4 \mathrm{~km})$ obtained by the receiver function inversion are used to set the search spaces in the uppermost crust. The density is estimated using the Nafe-Drake relation (e.g., Fowler, 1995; Ludwig et al., 1970) and the compressional wave velocity values are calculated using the relation between $v_{\mathrm{S}}$ and $v_{\mathrm{P}}\left(v_{\mathrm{P}}=1.73 v_{\mathrm{S}}\right)$, i.e., assuming Poissonian solids (e.g., Panza et al., 2007). When receiver function $h-k$ data are available and the variance is less than 0.05 , the ratio of $v_{\mathrm{P}}$ to $v_{\mathrm{S}}$ is set according to receiver function $h-k$ data. The a priori constraints are applied to ensure that the selected models are physically plausible. A model is considered acceptable if the objective function is less than $0.04 \mathrm{~km} / \mathrm{s}$.

The period range of the dispersion curves used for inversion varies from $4 \mathrm{~s}$ to $30 \mathrm{~s}$. The partial derivatives of the group velocity of Rayleigh wave (Rodi et al., 1975; Urban et al., 1993; Fang et al., 2010) show that the dispersion curve in this period range is sensitive to shear wave velocity structure from the near surface to about $50 \mathrm{~km}$ of depth, and insensitive to the shear wave velocity structure below $150 \mathrm{~km}$ (see also Panza, 1981). So we construct a starting model of $150 \mathrm{~km}$ thick. The search space of shear wave velocity between $50 \mathrm{~km}$ and $150 \mathrm{~km}$ depth is set to be $4.1-4.6 \mathrm{~km} / \mathrm{s}$ on the basis of previous surface wave tomography studies in North China (Huang et al., 2003). The shear wave velocity values below $150 \mathrm{~km}$ are taken from AK135 model.

Figure 4 shows an example of GA inversion with smoothing constraint. The differences among the different models are very small and the stability of the inversion proves the suitability of the chosen parameterization and constraints.

\section{Crustal and upper-mantle velocity structure}

We construct a 'favored model' developed through GA inversion at each grid point. Combining these 1-D isotropic models, we obtain a 3-D shear wave velocity model for the North China, with depth ranging from the surface to about $150 \mathrm{~km}$. The group velocity dispersion curves between $4 \mathrm{~s}$ and $30 \mathrm{~s}$ are most sensitive to the shear wave velocity structure from the near surface to the depth of $50 \mathrm{~km}$, therefore, in this paper, we focus on the interpretation of shear wave velocity structures in the crust.

In the study area, the $\mathrm{S}$ wave velocity horizontal patterns vary significantly with depth. At depth of $1 \mathrm{~km}$ (Figure 5a), the velocity structure is correlated with the sedimentary cover thickness. The boundary between $\mathrm{NCB}$ and the surrounding mountain ranges is clearly outlined. A broad low velocity zone is observed at NCB, which is due to the large thickness of sediments. Taihangshan and Yanshan uplifts are imaged as high velocity zones. The Quaternary intermountain basins, such as Yanqing-Huailai, Yangyuan-Yuxian, Datong and Zhangjiakou, show low velocity anomalies. In general, the $\mathrm{S}$ wave velocity map at $1 \mathrm{~km}$ depth correlates very well with the known surface geological structures.

In the $12 \mathrm{~km}$ depth map (Figure 5b), the areas of Jizhong depression, Cangxian uplift and Huanghua depression are mapped very well. The Jizhong and Huanghua depressions are mapped with relatively low velocities, while Cangxian uplift is mapped with high velocities. Our results indicate that the sedimentary cover in NCB can reach a thickness of about $10 \mathrm{~km}$. The velocity structures clearly reveal that the thickness of the sedimentary cover is different in the depression and uplift areas as indicated by earlier DSS and receiver function inversion studies. Jia and Zhang (2005) studied 

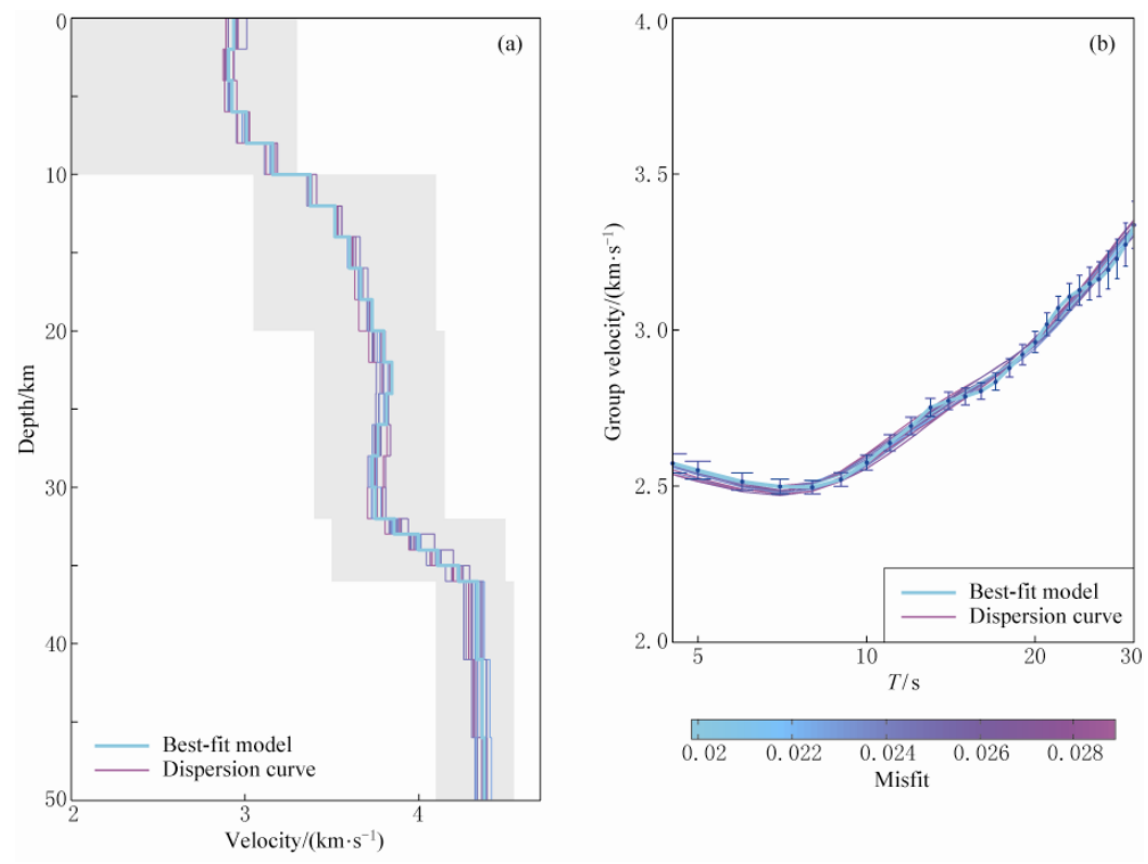

Figure 4 Inversion results of a cell $D_{42}$. (a) $\mathrm{S}$ wave velocity structures. The gray shaded area in (a) is the search space of S wave velocity in each layer. (b) Observed and synthetic dispersion curves. The error bars in (b) are standard errors of tomography.

the crust velocity structure of each sub-block in North China using 30 DSS profiles. Their results reveal that the thicknesses of the deposits in the Huanghua and Jizhong depressions are about $7-9 \mathrm{~km}$ and $6-10 \mathrm{~km}$, respectively. Zheng et al (2005) derived the shear wave velocity model in NCB by inverting the receiver functions obtained from 44 temporary seismic stations. Their results indicate that the sedimentary cover of NCB is about $2-12 \mathrm{~km}$ thick, which is consistent with our study.

At depth of $27 \mathrm{~km}$ (Figure 5c), a well-defined low velocity zone is observed in the Beijing-Tianjin-Tangshan region. This is consistent with many tomography studies in this region. Zhu and Zeng (1990) found a low velocity region in the Beijing-Tianjin-Tangshan region at $50 \mathrm{~km}$ depth, which extends to $100 \mathrm{~km}$ deep beneath Tangshan and Tianjin. Using regional seismic arrival data and simultaneous iterative reconstruction technique, Ding and Zeng (1994) revealed that a clear low velocity zone lied between Beijing and Tangshan in the depth range of $20-35 \mathrm{~km}$. Recent body wave tomography shows a low velocity zone in the lower crust beneath the Beijing-Tianjin-Tangshan region (Huang and Zhao, 2004 ) as well. A high conductivity layer has been found between 20 and $30 \mathrm{~km}$ depth under this region using magnetotelluric soundings (Liu et al., 1989). In our to- mography results, the low velocity zone in the BeijingTianjin-Tangshan region can be seen from $22 \mathrm{~km}$ to 30 $\mathrm{km}$. We infer that the low velocity zone is related to the upwelling of hot mantle material. Seismic refraction and reflection profiles across Tangshan indicate that there is a 3-5 km offset of Moho discontinuity beneath Tangshan (Zeng et al., 1988). The hot material of the uppermost mantle may migrate to the crust along the offset of Moho discontinuity. The intrusion of mantle material heats up the lower crust and hence can cause the reduction of seismic velocity.

At depth of $36 \mathrm{~km}$, the velocity map mainly represents the velocity structure in the lower crust and uppermost mantle in North China (Figure 5d). Different from the velocity patterns in the shallow crust, the eastern part of the study region exhibits high velocity anomalies, while low velocity anomalies are observed in the northwest part. This is because the thickness of the crust is different in the two parts. Reflection and refraction profiles in North China (Jia and Zhang, 2005) show that the crust is relatively thin in NCB, while it is thick in the northwest part of our study region: the crustal thickness is about 28-29 km in Bohai bay, about 35-36 $\mathrm{km}$ in Beijing and more than $40 \mathrm{~km}$ to the west of Taihangshan fault. 



Figure $5 \mathrm{~S}$ wave velocities at the depths 1 (a), 12 (b), 27 (c) and $36 \mathrm{~km}(\mathrm{~d})$.

From the $\mathrm{S}$ wave velocity maps at different depths, two important featuring zones can be seen: a) a high velocity zone near Datong, Shuozhou and Qingshuihe and b) a strong velocity gradient near the boundary between NCB and Yanshan-Taihangshan uplift. The high velocity zone near Datong, Shuozhou and Qingshuihe is observed in the depth range from $1 \mathrm{~km}$ to $23 \mathrm{~km}$. The high velocity zone is located at the northeastern margin of the Ordos block that shares the typical features of cratonic lithosphere and has not been affected by the North China craton re-activation. The block is characterized by low seismicity, low heat flow, positive vertical velocity gradient and lack of active fault and magmatic activity (Qiu et al., 2005). The inversion results reveal the stable characteristics of this region. Strong velocity gradient near the boundary between North China basin and Yanshan-Taihangshan uplift can be seen in the depth range from $1 \mathrm{~km}$ to $12 \mathrm{~km}$. Below $13 \mathrm{~km}$, the high and low velocity anomalies near Taihangshan front fault become blurry, and are visible only in some parts. Previous $\mathrm{P}$ wave tomography studies have shown that the Taihangshan front fault penetrates through the Moho discontinuity in some region (Huang and Zhao, 2004; Zhang et al., 2007). On the basis of our 3-D shear wave velocity model, we argue that the Taihangshan front fault extents to $12 \mathrm{~km}$ depth at least.

\section{Conclusions}

Rayleigh wave empirical Green's functions between pairs of stations across North China are extracted from cross correlations computed using 14 months of ambient noise data recorded at 200 temporary stations in North China from January of 2007 to February of 2008. 
Using dispersion data extracted from the Green's functions we constructed high-resolution Rayleigh wave group velocity maps in the period range from $4 \mathrm{~s}$ to $30 \mathrm{~s}$. These group velocity maps have then been inverted to obtain 3-D shear wave velocity variations in the study region using GA with smoothing constraint.

The sedimentary basins such as North China basin, Yanqing-Huailai basin and Datong basin are well outlined. A well-developed low velocity zone is observed in the Beijing-Tianjin-Tangshan region in the 22-30 km depth range, which may be related to the upwelling of hot mantle material. The high velocity zone near Datong, Shuozhou and Qingshuihe in the depth range from $1 \mathrm{~km}$ to $23 \mathrm{~km}$ reveals the stable characteristics of the Ordos block. The Taihangshan front fault extends to $12 \mathrm{~km}$ depth at least.

Acknowledgments The authors are grateful to two anonymous reviewers for valuable suggestions and comments. This work is supported by the National Natural Science Foundation of China (Nos. 40774038 and 90914005), Basic Research Project of Ministry of Science and Technology of China (No. 2006FY110100) and National Nonprofit Institute Research Grant of Institute of Geophysics, China Earthquake Administration (IGPCEA) (No. DQJB09B08). This work is also supported by Italian MUR and University of Trieste in the framework of the Internationalization $\mathrm{PhD}$ Program (2004-2006). Contribution No. is 10FE3008, IGPCEA.

\section{References}

Chang C (1991). Geological characteristics and distribution patterns of hydrocarbon deposits in the Bohai Bay Basin, east China. Mar Pet Geol 8: 98-106.

China Earthquake Network Center (2008). Seismic Data Management and Service System. http://www.csndmc.ac.cn/newweb/index.jsp.

De Nisco G, Nunziata C, Vaccari F and Panza G F (2008). Shear wave velocities from noise correlation at local scale. In: Santini A and Moraci N eds. 2008 Seismic Engineering Conference Commemorating the 1908 Messina and Reggio Calabria Earthquake (vol. 1020). American Institute of Physics, Maryland, 354-361.

Deng Q D, Zhang P Z and Ran Y K (2004). Distribution of Active Faults in China (1:4 000 000). Science Press, Beijing, 1 (in Chinese).

Department of Seismic Hazard Prevention, China Seismological Bureau (1995). China Historical Strong Earthquake Catalogue (23 Century BC-1911). Seismological Press, Beijing, $514 \mathrm{pp}$ (in Chinese).

Department of Seismic Hazard Prevention, China Seismological Bureau (1999). China Current Earthquake Catalogue (1912-
1990). China Science and Technology Press, Beijing, 673 pp (in Chinese).

Ding Z F and Zeng R S (1994). The 3D velocity structure inversion in Beijing-Tianjin-Tangshan area by using local earthquake data. North China Earthquake Sciences 12(2): 14-20 (in Chinese with English abstract).

Ditmar P G and Yanovskaya T B (1987). Generalization of Backus-Gilbert method for estimation of lateral variations of surface wave velocities. Izv Acad Sci USSR, Phys Solid Earth 23(6): 470-477.

Fang L H, Wu J P, Ding Z F and Panza G F (2010). High resolution Rayleigh wave group velocity tomography in North China from ambient seismic noise. Geophys J Int 181: 1 1711 182, doi:10.1111/j.1365-246X.2010. 04571.x.

Feng C C and Teng T L (1983). Three-dimensional crust and upper mantle structure of the Eurasian continent. J Geophys Res 88: 2 261-2 272.

Fowler C M R (1995). The Solid Earth: An Introduction to Global Geophysics. Cambridge University Press, New York, 1-637.

Huang J and Zhao D (2004). Crustal heterogeneity and seismotectonics of the region around Beijing, China. Tectonophysics $\mathbf{3 8 5}$ : $159-180$.

Huang Z, Su W, Peng Y, Zheng Y and Li H (2003). Rayleigh wave tomography of China and adjacent regions. J Geophys Res 108(B2): 2 073, doi:10.1029/2001JB001696.

Jia S X and Zhang X K (2005). Crustal structure and comparison of different tectonic blocks in North China. Chinese J Geophys 48(3): 611-620 (in Chinese with English abstract).

Lei J, Xie F, Lan C, Xing C and Ma S (2008). Seismic images under the Beijing region inferred from $\mathrm{P}$ and $\mathrm{PmP}$ data. Phys Earth Planet Int 168: 134-146.

Levshin A L, Ratnikova L and Berger J (1992). Peculiarities of surface wave propagation across Central Eurasia. Bull Seismol Soc Am 82: 2 464-2 493.

Li H, Su W and Wang C (2009). Ambient noise Rayleigh wave tomography in western Sichuan and eastern Tibet. Earth Planet Sci Lett 282: 201-211.

Li S L, Mooney W D and Fan J C (2006). Crustal structure of mainland China from deep seismic sounding data. Tectonophysics 420: 239-252.

Lin F C, Ritwoller M H, Townend J, Bannister S and Savage M K (2007). Ambient noise Rayleigh wave tomography of New Zealand. Geophys J Int 170(2): 649-666.

Liu G, Sun J and Liu J (1989). The electrical structure of the crust and upper mantle in North China. In: Ma X Y ed. Lithospheric Dynamics Atlas of China. China Cartographic Publishing House, Beijing, 59-62 (in Chinese).

Ludwig W J, Nafe J E and Drake C L (1970). Seismic refraction. In: Maxwell A E ed. The Sea. Vol. 4, Part 1. Wiley-Interscience, New York, 53-84.

Luo Y, Chong J J, Ni S D, Chen Q F and Chen Y (2008). Moho depth and sedimentary thickness in Capital region. Chinese $J$ Geophys 51(4): 1 135-1 145 (in Chinese with English abstract).

Panza G F (1981). The resolving power of seismic surface waves with respect to crust and upper mantle structural models. In: 
Cassinis R ed. The Solution of the Inverse Problem in Geophysical Interpretation. Plenum Pub. Corp., New York, 39-77.

Panza G F, Peccerillo A, Aoudia A and Farina B (2007). Geophysical and petrological modeling of the structure and composition of the crust and upper mantle in complex geodynamic settings: The Tyrrhenian Sea and surroundings. Earth Sci Rev 80: 1-46.

Pontevivo A and Panza G F (2006). The lithosphere-asthenosphere system in the Calabrian arc and surrounding seas - Southern Italy. Pull Appl Geophys 163: 1617-1 659.

Qi C, Zhao D, Chen Y, Chen Q and Wang B (2006). P and S-wave velocity structures and its relationship to strong earthquakes in the Chinese capital region. Chinese J Geophys 49(3): 805-815 (in Chinese with English abstract).

Qiu R Z, Deng J F, Zhou S, Li J F, Xiao Q H, Wu Z X and Liu C (2005). Lithosphere types in North China: Evidence from geology and geophysics. Science in China (Series D) 48(11): 1809-1 827 (in Chinese with English abstract).

Ritzwoller M H and Levshin A L (1998). Eurasian surface wave tomography: Group velocities. J Geophys Res 103: 4 8394878.

Rodi W, Glover P, Li T M C and Alexander S S (1975). A fast, accurate method for computing group-velocity partial derivatives for Rayleigh and Love waves. Bull Seismol Soc Am 65(5): 1 105-1 114.

Sabra K G, Gerstoft P, Roux P, Kuperman W A and Fehler M C (2005). Surface wave tomography from microseisms in Southern California. Geophys Res Lett 32: L14311, doi: 10.1029/2005GL 023155.

Shapiro N M, Campillo M, Stehly L and Ritzwoller M H (2005). High resolution surface wave tomography from ambient seismic noise. Science 307: 1615-1 618.

State Seismological Bureau (1986). Geophysical Exploration Results of Crust and Upper Mantle in China. Seismological Press, Beijing, 52-124 (in Chinese).

Teng J W, Zhang Z J and Bai W M (2003). Lithosphere Physics. Science Press, Beijing, 1-990 (in Chinese).

Urban L, Cichowicz A and Vaccari F (1993). Computation of analytical partial derivatives of phase and group velocities for Rayleigh waves with respect to structural parameters. Stud Geophys Geod 37: 14-36.

Wang J, Liu Q Y, Chen J H, Li S C, Guo B and Li Y (2009a). The crustal thickness and Poisson's ratio beneath the Capital Circle Region. Chinese J Geophys 52(1): 57-66 (in Chinese with English abstract).

Wang W L, Wu J P and Fang L H (2009b). Crust and upper mantle S-wave velocity structure beneath Tanghai-Shangdou seismic array profile. Chinese J Geophys 52(1): 81-89 (in Chinese with English abstract).
Wang Y P, Deng Q D and Zhu S L (1989). Lithospheric dynamics of North China. In: Ma X Y ed. Lithospheric Dynamics Atlas of China. China Cartographic Publishing House, Beijing, 62 (in Chinese).

Wu J P, Ming Y H and Zeng R S (2001). Smooth constraint inversion technique in genetic algorithms and its application to surface wave study in the Tibetan Plateau. Acta Seismologica Sinica 14(1): 49-57.

Xu W W and Zheng T Y (2005). Distribution of Poisson's ratios in the northwestern basin-mountain boundary of the Bohai Bay Basin. Chinese J Geophys 48(5): 1077-1 084 (in Chinese with English abstract).

Yang Y, Ritzwoller M H, Levshin A L and Shapiro N M (2007). Ambient noise Rayleigh wave tomography across Europe. Geophys J Int 168: 259-274.

Yanovskaya T B (1997). Resolution estimation in the problems of seismic ray tomography. Izv Phys Solid Earth 33(9): 762-765.

Yanovskaya T B and Ditmar P G (1990). Smoothness criteria in surface wave tomography. Geophys J Int 102: 63-72.

Yanovskaya T B, Kazima E and Antonova L (1998). Structure of the crust in the Black Sea and adjoining region. $J$ Seismol 2: 303-316.

Yao H, van der Hilst R D and de Hoop M V (2006). Surface-wave tomography in SE Tibet from ambient seismic noise and two-station analysis. I. Phase velocity maps. Geophys J Int 166: 732-744, doi:10.1111/j.1365-246X.2006.03028.x.

Zeng R S, Lu H X and Ding Z F (1988). Seismic refraction and reflection profiles across Tangshan epicentral region and their implication to seismogenic processes. Chinese $J$ Geophys 31(4): 383-398 (in Chinese with English abstract).

Zhang L, Liu J S, Hao T Y, Liu J H and Xu Y (2007). Seismic tomography of crust and upper mantle in Bohai Bay basin and surrounding area. Science in China (Series D) 37(11): 14441455 .

Zheng S, Sun X, Song X, Yang Y and Ritzwoller M H (2008). Surface wave tomography of China from ambient seismic noise correlation. Geochem Geophys Geosyst 9: Q05020, doi: 10.1029/2008 GC001981.

Zheng T, Zhao L and Chen L (2005). A detailed receiver function image of the sedimentary structure in the Bohai Bay Basin. Phys Earth Planet Inter 152: 129-143.

Zhu L P and Zeng R S (1990). Three-dimensional P-wave velocity structure under the Beijing network area. Chinese J Geophys 33(3): 267-277 (in Chinese). 